\title{
La recepción del Maestro Eckhart en Bruno Taut: \\ para una arquitectura sin porqué
}

\section{Oscar Federico Bauchwitz*}

Resumen Análisis de la relevancia del pensamiento del Maestro Eckhart en el contexto utópico de la obra del arquitecto alemán Bruno Taut, con el objetivo de contribuir con la constitución de un sentido para pensar lo que se indica con la expresión arquitectura sin porqué.

Palavras clave: arquitectura expresionista, Bruno Taut, Maestro Eckhart.

\section{A recepção de mestre Eckhart em Bruno Taut: para uma arquitetura sem porquê}

Resumo Análise da relevância do pensamento de Mestre Eckhart no contexto utópico da obra do arquiteto alemão Bruno Taut, com o objetivo de contribuir com a constituição de um sentido para pensar o que se indica com a expressão arquitetura sem porquê.

Palavras-chave: arquitetura expressionista, Bruno Taut, Mestre Eckhart.
The meister eckhart's reception in bruno taut: for an architecture without why

Abstract Analyse of the relevance of Meister Eckhart's thinking in the utopian context of the work of the German architect Bruno Taut, aiming to contribute to the constitution of a sense to think what is indicated with the expression architecture without why.

Keywords: architecture expressionist, Bruno Taut, Meister Eckhart. 
Cuando se trata de conseguir lo alcanzable, tenemos que conocer y desear siempre lo inalcanzable. Sólo somos huéspedes en esta tierra, y nuestra patria está en lo superior, en asimilarnos y someternos a ello - Bruno Taut

nvestigar la la recepción del Maestro Eckhart en la concepción arquitectónica de Bruno Taut no sólo permite investigar la pertinencia y la adecuación del pensamiento eckhartiano respecto de los intereses del arquitecto, sino además experimentar que la historia de la filosofía avanza siempre y cuando sea actualizada por sus intérpretes, sean filósofos de oficio o no. ${ }^{2}$ Es de agradecer que Taut haya proporcionado una perspectiva posible del pensamiento eckhartiano, descubriendo una faceta casi inadvertida: servir de bandera para una transformación arquitectónica colaborando con el sentido que conduce a la arquitectura - y al arte en general - a su propia esencia. Poner al descubierto este sentido es lo que caracteriza la lectura tautiana del Maestro Eckhart -lo que aquí se indica con la expresión una arquitectura sin porqué. Más allá de señalar cómo, dónde y de qué Taut se apropia del pensamiento eckhartiano en un contexto ya de por sí "activista", querríamos indicar algunos aspectos que, a nuestro ver, permiten pensar de un modo más amplio qué puede encontrarse uno en la obra de Eckhart que haya contribuido a fundamentar la concepción tautiana de la arquitectura y del arquitecto como constructor de mundos, más allá de las citaciones explícitas que se puedan encontrar y en contexto en que aparecen.

\section{La libertad del no-querer: vivir sin porqué}

Maestro Eckhart es un pensador de la libertad. Consecuencia de sus presupuestos metafísicos y religiosos, pensar la libertad significa pensar cómo debe actuar el ser humano de un modo esencial, es decir, que debe aprender a habitar un mundo emulando la vida y al propio dios, ejerciendo una libertad plena no condicionada por un querer determinado, sino una libertad que brota y se mueve sin porqué.

En sus Pláticas Instructivas, Eckhart argumenta que la libertad de una acción es la que imprime vigor y dignidad "a la oración y a la obra". Y cuanto más libre, cuanto más procede de un ánimo o disposición (Gëmut) libre, tanto más se muestra la acción humana como capaz de hacer todas las cosas, casi como si fuera "todopoderosa". El hombre libre

no se perturba por nada ni está atado a nada, ni tiene atado lo mejor de sí mismo a ningún modo, ni mira por lo suyo en cosa alguna, sino que está abismado completamente en la queridísima voluntad de Dios, luego de haberse despojado de lo suyo. El hombre no puede ejecutar jamás una obra, por insignificante que sea, sin que

* Oscar Federico Bauchwitz é Filósofo, Professor Titular de Metafísica do Departamento de Filosofia da Universidade Federal do Rio Grande do Norte, ORCID $<$ https://orcid.org/0000-00023240-0434> ésta reciba su fuerza y virtud de tal disposición. (MEISTER ECKHART, 2013, Pláticas instructivas 2, p.110)

Según esta definición, la disposición humana se encuentra libre cuando puede disfrutar de un estado donde su voluntad ya no es propiamente la suya, sino la que proviene 
1 Este trabajo contó con los auspicios del Programa Institucional de Internacionalização (PRINTUFRN-CAPES), en la modalidad de "Professor Visitante Sênior no Exterior", desarrollado en la Universidad de Sevilla en 2019.

2 Algunos estudios han abordado y analizado la presencia del Maestro Eckhart en la obra de Bruno Taut. Entre ellos, se destacan: SCHIRREN, 2001; ÁBALOS, 1997; CIRLOT, V. 2013. de la voluntad divina. En tal estado de ánimo, la acción humana ya no se perturba o está atada a la búsqueda de algún fin que no sea la experiencia fundamental de que puede, actuando desde la libertad, querer y ser como dios. Hasta aquí el sentido místico de esta definición de un actuar libre, ese sentimiento de "haberse despojado" de sí mismo en nombre de la voluntad divina podría indicar un sentimiento cristiano de carácter muy poco heterodoxo. Heidegger señala este carácter para advertir que su Gelassenheitse refiere a la época de la metafísica consumada y del mundo técnico, muy lejos de cualquier disposición de cumplir designios divinos, supuestamente enseñada por Eckhart. La "renuncia despojada" que caracteriza la acción libre corresponde a presupuestos metafísicos que abren la posibilidad existencial de que el ser humano actúe como dios. Es decir, por medio de la experiencia de la libertad el ser humano puede alcanzar su máxima semejanza con dios. Por ello, despojarse de sí mismo no sería como abdicar de algo para que otro, en este caso dios, se ponga en su lugar, a menos que "dios" signifique "más allá de dios".

Lo que se experimenta por medio de la libertad no es la permanencia ni de uno ni de otro, ni humano ni dios, sino un mismo fondo de indistinción. Que el ser humano despojado y libre se encuentre como "abismado" en la voluntad divina evidencia el origen extraordinario e inefable de todas las cosas, del humano y también de "dios". Heidegger no desconoce este sentido. Si cuestiona a Eckhart, no es para deshacerse de su pensamiento, sino para cuidar y evitar que esa palabra de clara inspiración eckhartiana - Gelassenheit -, que Heidegger utiliza para indicar la conducta recomendada para hacer frente al furor de la técnica moderna, sea tomada a la ligera.

La consideración que Heidegger tiene por Eckhart resulta patente en diversos momentos de su obra -ampliamente discutidos por la academia. No es oportuno indicar ahora estos momentos, pero al menos una cita que hace Heidegger puede mostrar su reconocimiento al pensamiento eckhartiano, sin restricciones, como fuente de inspiración para pensar cómo construir y habitar esencialmente un mundo marcado por la "estructura de emplazamiento" (Gestel/). Dice Heidegger: "Observemos, considerando esto, una expresión de Meister Eckhart, mientras la pensamos desde su fundamento. Ella reza: "los que no tienen una gran esencia, cualquiera sea la obra que hagan, no resultará nada" (HEIDEGGER, 2008, p.21). Heidegger se refiere a la utilidad del despojamiento que, según Eckhart, uno debe realizar interior y exteriormente, es decir, una conquista desde el fondo del alma que también atañe a su mundo. Estar despojado o desasido constituye la disposición adecuada desde la cual debe actuar el ser humano para cumplir con su propio ser $\mathrm{o}$, al menos, que intente darlo a conocer. Para Eckhart, "la gente nunca debería pensar tanto en lo que tiene que hacer; tendría que meditar más bien sobre lo que son" (2013, p. 113). No dice que la conducta humana deba ser la de abandonar el mundo y huir para una desierta soledad, sino que recomienda un cierto cuidado con las cosas de las que uno se ocupa y, sobre todo, la necesidad de una meditación sobre sí mismo, sobre el ser humano y su modo libre de ser. Nada es más elevado en lo humano que su semejanza con dios. Por ello, al actuar, el ser humano no tendría por qué preocuparse de nada como no sea de cumplir con aquello que lo sitúa tan cerca de la naturaleza divina. Así lo explica Eckhart:

Por santas que sean las obras, no nos santifican en absoluto en cuanto obras: sino en cuanto somos santos y poseemos el ser, en tanto santificamos todas nuestras obras, ya se trate de comer, de dormir, de estar en vigilia o de cualquier cosa que sea. Quie- 
nes no tienen grande el ser, cualquier obra que ejecuten, no dará resultado. Sabe por lo dicho que uno tiene que cifrar todo su empeño en ser bueno y no [insistir] tanto en lo que uno hace o en la índole de las obras, sino en cómo es el fundamento de las obras. (2013, Pláticas Instructivas 4, p.113).

Es notable el esfuerzo eckhartiano de evidenciar el carácter extraordinario de una acción verdaderamente libre. Ya se trate de comer, dormir, estar en vigilia o de cualquier otra cosa, en todas sus obras, el ser humano por ser como es - y no por un querer - santifica su acción. Una acción que no se condiciona por un querer, o por mejor decir, está condicionada por la búsqueda de aquello que brota del fondo del ser y no de una necesidad exterior apremiante.

Para el maestro de Erfurt, actuar de modo a corresponder a un querer inusual sólo es posible si se reconoce el fondo desde el cual todo tiene origen, aquello desde el cual todo lo que puede ser brota tal cual es. En el Sermón 5b, leemos:

Ahí el fondo de Dios es mi fondo, y mi fondo el de Dios. Ahí vivo de lo mío, así como Dios vive de lo suyo. [...] Desde este fondo más entrañable has de obrar todas tus obras sin porqué alguno. Mientras hagas tus obras por el reino de los cielos o por Dios o por tu eterna bienaventuranza, es decir, desde fuera, realmente andarás mal. (2013, p.308)

"Has de obrar todas tus obras sin porqué alguno": al modo de un extraordinario imperativo la acción se encuentra ahora dirigida hacia algo más allá de todo querer. Ya no se contenta con reino de los cielos, dios o determinada bienaventuranza eterna, no corresponde a ninguna norma moral, sino que busca ser tan libre cuanto la vida misma. Así lo explica Eckhart:

Si alguien durante mil años preguntara a la vida: "¿Por qué vives?"... ésta, si fuera capaz de contestar, no diría sino: "Vivo porque vivo". Esto se debe a que la vida vive de su propio fondo y brota de lo suyo; por ello vive sin porqué justamente porque vive para si misma. Si alguien preguntara entonces a un hombre veraz, uno que obra desde su propio fondo: "¿Por qué obras tus obras?"[...] él, si contestara bien, no diría sino: "Obro porque obro" (2013, p.308).

Como la vida misma, que brota de lo suyo y vive para sí, de tal modo debe actuar el ser humano, desde su propio fondo, desde lo suyo y para lo suyo. Por ello, él obra porque obra, no busca razones que lo muevan porque ha podido ver lo que le pertenece y guarda dentro de sí, la posibilidad más elevada de llegar a ser como dios, siempre que logre separarse de las diferencias que pueden impedir tal reunión.

Eckhart valoriza su enseñanza por la amplitud y la fuerza del no-querer. Aquello que ha sido alcanzado por medio de una interpretación metafísica se muestra como una posible experiencia existencial. Vivir sin porqué no es algo que se aprenda mediante la huida del mundo, sino cultivando una perspectiva que más allá de las diferencias presentes en su mundo, permite ver lo que, absolutamente, sólo cobija indistinción. De tal modo, esté donde esté o con quién sea que esté, inmerso en la multiplicidad de las diferencias, el ser humano posee a dios: 
3Según Haas, "el verbo alemán abescheiden significa separarse, apartarse, irse, despedirse, morir, resolverse, [...] en la palabra alemana moderna Abgeschiendenheit, que implica 'lugar remoto, alejado de los hombres' puede resonar, indudablemente, en el modo en que Eckhart la utiliza. No obstante, es preciso invertir de inmediato el significado concreto a un significado espiritual" (2002, p.48) lo tiene en todos los lugares, en la calle y en medio de toda la gente exactamente lo mismo que en la iglesia o en el desierto o en la celda. [...] Y así como ninguna multiplicidad lo puede distraer a Dios, así nada puede distraer ni diversificar a este humano ya que es uno solo en lo Uno, donde toda multiplicidad es una sola cosa y una no-multiplicidad. (MEISTER ECKHART, 2013, Platicas Instructivas, 6, p.114)

Es en un mundo de diferencias y multiplicidad dónde el ser humano habita, por ello la necesidad de Eckhart de advertir que no recomienda una huida, sino de aprender a "tener un desierto interior" habitado por dios y por tanto, sin multiplicidad. Es, por tanto en un mundo que cotidianamente demanda el cuidado (Sorge) humano, donde ya y siempre se sitúa la existencia humana. Eckhart admite esta situación pero no ve impedimentos en ello. Considera que el ser humano "en esta vida no puede ser sin actividad (Tätigkeit) [...], le hace falta aprender a poseer a su Dios en todas las cosas y no sentir impedimentos en ninguna obra ni lugar alguno" (2013, Pláticas Instructivas 7, p. 121). Pertenece al modo del ser-humano (Menschsein) estar junto y ocuparse de la multiplicidad de las cosas que lo rodean, y eso de modo tan esencial que no podría configurar un obstáculo infranqueable. Tan sólo hace falta poseer a dios en todas las cosas y para ello debe actuar libremente. Si actuara así en sus obras, "dios resplandecería, sin duda, tan de-veladamente en la obra mundana como en la más divina" (p. 120).

Heredero de una tradición teofanista, Eckhart reconoce el poder de la plena libertad como el único acceso a la experiencia de lo divino. En Del desasimiento (Von Abgeschiedenheit) ${ }^{3}$ escribe: "el alma tiene una entrada secreta a la naturaleza divina donde se le anonadan todas las cosas. En esta tierra la tal entrada no es sino el desasimiento puro" (2013, p. 257). Eckhart enaltece el desasimiento sobre todas las demás virtudes que se ejercen con la mirada puesta en la creatura, mientras que el desasimiento dirige el esfuerzo humano para la semejanza con el creador. Aquí la conocida enseñanza: "estar vacío de todas las creaturas significa estar lleno de Dios y estar lleno de todas las creaturas, significa estar vacío de Dios". El ser desasido suscita un vaciamiento que da lugar a la irrupción de dios, aboliendo toda alteridad entre dios y el ser humano y promoviendo el retorno a un estado originario develado por la abolición de todas las diferencias. No sólo las creaturas y el ser humano tienen su origen en tal estado de indistinción sino que también dios deviene "dios", por medio de las diferencias consecuentes e inherentes al acto creador.

En la no alteridad lograda por el desasimiento reside la libertad por excelencia. Eckhart se refiere a un lugar donde dios y el ser humano coinciden. Este lugar es custodia y luz del espíritu, es también chispa (Fünklein), pero, sobre todo, es la fuerza que vigora en y por la libertad. Es tan libre de todo nombre y de toda forma que, rigurosamente, no puede ser conocida por el ser humano o por dios. Ahí donde vigora esa fuerza, se instaura el lugar de lo libre, un lugar que Eckhart denomina de "ciudadela" (Bürglein), donde necesariamente no el dios, sino la deidad despojada de sus nombres y propiedades personales es acogida y encuentra su lugar, el fondo del alma humana. La construcción de esta ciudadela es el destino del ser separado, el de dar lugar a dios. Sin embargo, una vez más, Eckhart nos provoca con otro desafío, que es el de superar cualquier imagen previa acerca de lo que nos quiere indicar. Eso significa que la propia idea de "lugar" tenga un sentido renovado, la construcción de esta ciudadela se da en el alma, es fruto de un despojamiento radical del mundo, de 
4 Alain De Libera observa que en el texto alto medio alemán hay cierto juego de palabras de difícil traducción: zuoganges (Zugang), acceso y zuohangendes (Anhaftendes), accidente en el sentido de "I'arrivant", de lo que adviene del exterior. Por otro lado, înhangen (Einwohnen) "correspond à l'idée de résidence, de fixation de soi-même, de manence intéreure, d'im-manence ou d'attache intérieure de Dieu". La traducción francesa dice: "Dieu est une fixation à sa pure et propre essentialité à quoi rien n'arrive d'extérieur" y, como traducción alternativa "Dieu est une attache intérieure à sa pure et propre essentialité, à quoi rien ne s'attache de l'extérieur" (DE LIBERA, p.240). dios y de todo yo ensimismado. Vaciado de todo querer, por medio del ser separado, el ser humano entraría en aquél lugar que es suyo y en el cual dios necesariamente encuentra su descanso. Este vaciamiento y la nada que se asoma, no es como una nada nihilista o una negligencia para con las cosas del mundo. Al contrario, con su pensamiento místico, en la medida que abre un sentido extraordinario para habitar la tierra, salva o mundo! Es que a ese vaciarse corresponde un saber del mundo. Un saber que sabe, que tiene sabor. Como escribe el Maestro: "todas las cosas tienen para él sabor (schmecken) de dios y la imagen de dios se le hace visible desde en todas las cosas" (2013, Pláticas Instructivas 6, p.117). Sólo mediante el estar despojado, el ser humano puede obtener la experiencia de un extraordinario habitar que otra cosa no es que dios mismo. Al comentar un pasaje paulino $(1$ TIM 6, 16) de larga repercusión en la tradición neoplatónica cristiana, escribe Eckhart:

Por eso dice Pablo 'Dios mora en una luz a la cual no hay acceso (zuoganges)'. Él es una inhabitación (înhangen) en su propia esencia pura en la cual no hay nada adherido (zuohangendes). Lo que posee 'accidente' (zuoval) debe desaparecer. Él es un puro estar-en-si-mismo donde no hay ni esto ni aquello, pues lo que hay en dios, es dios (2013, Sermón 3, p.288).4

Frente a la autoridad paulina - y acomodándola a su perspectiva -, Eckhart acepta que la morada divina sea inaccesible, o al menos lo es cuando se refiere a lo que no es necesario, sino accidental. En tal morada, no hay lugar para diferencias, nada que sea esto o aquello, tan sólo la experiencia del existir insistente de la vida misma, la descubierta de la posibilidad de habitar el mundo de modo a construir lugares que concedan tal experiencia, el vivir sin porqué.

Esta breve exposición nos permite reconocer en el Maestro Eckhart un vocabulario cercano a los intereses de un arquitecto deseoso de pensar y renovar el sentido de la arquitectura y de la sociedad. "Vida", "muerte", "mundo", "tierra", "desierto", "ciudadela", "castillo", "lugar", "entrada", "exterior", "interior", "lleno", "vacío", "habitación", "fondo", "elevado" son indicaciones que podrían colaborar con una especie de topología metafísica que permitiera fundar una arquitectura y engendrar una transformación del mundo construido y se habitado desde lo más fondo, lo sinfondo, lo sin porqué.

\section{Bruno Taut y la arquitectura sin porqué}

La originalidad de la arquitectura de Bruno Taut puede comprobarse no sólo en los edificios que ha construido, sino también en los proyectos no concretizados y que corresponden a una nueva concepción de la arquitectura marcada por un fuerte carácter activista en aras de la transformación de la sociedad y de la ciudad. Las referencias explícitas al Maestro Eckhart pertenecen a esta concepción y colaboran con la búsqueda tautiana de pensar una arquitectura desde una perspectiva espiritual más allá de su vocación práctica y útil. Taut menciona a Eckhart en al menos dos ocasiones: en una correspondencia dentro de la Cadena de Cristal, donde revindica el carácter inusual del nihilismo eckhartiano y en su conocido La corona de la ciudad (1919).

La Cadena de Cristal (Die Glaserne Kette) se desarrolló entre 1919 y 1920 y consistía básicamente en el intercambio de correspondencias de carácter utópico entre un selecto 
5 "He leído el Zaratustra de Nietzsche en los últimos tres años libro de enorme y seria vitalidad", Letter to Marx Taut apud BOYD WHYTE (1982, p.85). grupo de arquitectos que enaltecían las cualidades del vidrio desde una perspectiva visionaria y futurista de la sociedad y de las ciudades. En una carta de 19 de octubre de 1920, Taut describe su imagen del mundo (Weltbild) y explicita su relación con el pensamiento del Maestro Eckhart. Para Taut el conocimiento humano se constituye al modo de una esfera y sea lo que fuere que se encuentre más allá de esa esfera no debería sufrir la interferencia humana. Reconoce, sin embargo, que el anhelo del artista y su creatividad tienen origen en el sentido fundamental de ese más allá, el "más pleno sentido del reino de lo indecible y para el cual tenemos sólo una palabra: 'Nada'. Maestro Eckhart: tu sólo tienes "Nada" en ti - o: Dios es 'Nada'. [...] Tal vez eso te parezca nihilismo, pero para mí es una afirmación importante" (BOYD WHYTE, 1985, p.159). La interpretación y el uso que hace Taut del pensamiento eckhartiano están lejos de ser desdeñables y, al menos, dos observaciones son necesarias: una es el sentido que el maestro renano encuentra en la "nada" que se predica de dios, es decir, Taut reconoce en la palabra eckhartiana una descubierta semántica extraordinaria que, a la vez que expresa un sentido divino, habla también de lo humano y de su capacidad de franquearse el acceso a ese más allá habitado por dios. Otra observación es que Taut advierte cierta ambigüedad en la palabra nihilismo, por un lado, un nihilismo "místico", consecuencia de una metafísica que proclama la negatividad e indistinción de lo Uno, tan propio del neoplatonismo del cual Eckhart es uno de sus exponentes, y por otro, aquél nihilismo que Taut se propone superar, aquél mismo que Nietzsche advirtió como "el más inhóspito de todos los huéspedes" (NIETZSCHE, 2 [127], 1999, p.125).

Nietzsche, que tanta influencia ejerció en el movimiento expresionista y en el propio Taut, $^{5}$ se proclamaba el primer nihilista perfecto por haber logrado dejar atrás el desierto de la devastación de lo humano y de la ausencia de valores, un desierto que no permite sino verse a sí mismo sin orientación. Al ser capaz de aceptar la muerte de dios y su consecuencia moral del "todo en vano hasta ahora" (NIETZSCHE, 7 [8] D, 1999, p.293) y de "la falta de respuestas al por qué" (NIETZSCHE, 9 [35], 1999, p.350), consignas emblemáticas del nihilismo pasivo, Nietzsche celebra haber superado la falta de motivación de aquél nihilista que, desprovisto de dios, no encuentra fuerza suficiente para seguir adelante y se ve a sí mismo en una situación sin-sentido y sin valores que pudieran lastrar el ejercicio de su propia libertad. Sólo porque Nietzsche descubre la posibilidad del eterno retorno como una hipótesis para valorar la existencia desde su elemento más frágil y efémero - el instante - puede alzar la dignidad de la creatividad humana a un nivel más allá de lo simplemente humano, "el más allá" (das Jenseit) nietzschiano que emerge y coincide con la posibilidad de soportar tamaña efémera fragilidad (NIETZSCHE, 5 [6], 1999, p.186). Llama la atención el hecho de que también Nietzsche, en La Gaya Ciencia, recuerde a Eckhart, aunque sin citar específicamente el Sermón 52, preguntándose si "hoy en día ¿no nos gustaría decir respecto a la Moral, como el Maestro Eckhart: ruego a dios que me vacíe de dios?" (NIETZSCHE, 2005, p. 531).

Y es aquí donde la observación de Taut se muestra más pertinente. "Tal vez eso te parezca nihilismo" reconoce Taut, es decir, para aquél que aún se encuentra perdido en la falta de respuestas y de valores, el pensamiento eckhartiano poco o casi nada puede mostrar, sin embargo, la palabra eckhartiana "es una afirmación importante". Si uno considera la nada "eckhartiana" y la nada "nihilista" llegará a la conclusión que una similitud entre ambas no es sino una falta de entendimiento de las diferencias 
abisales entre ambas. Para Eckhart, es la expresión más adecuada que el lenguaje y el pensamiento pueden alcanzar respecto al fundamento de todas las cosas y a la libertad humana. Lejos de denotar un desprecio por el mundo, la nada eckhartiana señala la posibilidad humana de experimentar la libertad en un sentido extraordinario y - por qué no? - sagrado e inefable. El nihilista, criticado y superado por Nietzsche, permanece sin encontrar un sentido para la existencia. Al recordar las palabras de Eckhart, Nietzsche comprende que el renano no corresponde al dios "muerto", el dios de la tradición metafísica y moral, sino a un dios cuyo sentido brota de una experiencia individual, la experiencia de la nada. Es con esa perspectiva que Taut entiende el pensamiento de Eckhart, no como nihilismo fragilizado o pasivo, sino como una posibilidad concreta de libertad, como construcción de lugares propicios para la experiencia de lo libre. Tratase de conquistar un vacío, y en éste ubicar - dar lugar -, preservar, dejar ver y ser tomado por el sentido extraordinario de lo sin porqué.

La segunda referencia a Eckhart está en La Corona de la Ciudad (Die Stadkrone), obra que reflexiona y concibe una nueva concepción de la arquitectura y del papel del arquitecto, al tiempo que proyecta una nueva ciudad. En el primer párrafo Taut escribe:

¡Mil veces sea alabada la grandeza de la arquitectura! La arquitectura satisface la necesidad del hombre de protegerse contra las inclemencias del tiempo y contra los múltiples peligros a los que se expone si se enfrenta a la naturaleza sin una morada que lo cobije. El papel que desempeña en la existencia humana parece, por tanto, más bien modesto: el de un 'arte útil' (Zweck kunst) que satisface las necesidades prácticas de forma agradable. Sólo cuando los deseos humanos van más allá de lo meramente práctico y necesario, cuando se alcanza el excedente del bienestar que el lujo reclama, la arquitectura parece que se hace más presente y que manifiesta su propio yo con mayor intensidad. Entonces ya no da la sensación de estar tan estrechamente vinculada a la necesidad, y de ahí que sólo entonces pueda ser verdaderamente contemplada como arte (1997, p.37).

Taut reconoce el papel destinado a la arquitectura pensado desde la utilidad y la practicidad de sus obras con vistas a la satisfacción de las demandas básicas de la habitación humana. Sin embargo, observa que justamente cuando esas mismas demandas se encuentran ya atendidas, es cuando la arquitectura puede alcanzar su propia esencia y da a conocer su identidad, "manifiesta su propio yo con mayor intensidad". Sólo entonces, cuando la arquitectura ya ha cumplido su papel utilitario es que puede dar un paso más y mostrarse como arte. Desprovista de toda necesidad apremiante, la arquitectura puede promover una reflexión fundamental sobre el modo del ser humano habitar y construir el mundo, sin que una razón o un porqué anticipe y determine su habitación. Más allá de las necesidades materiales que propician abrigo y refugio al ser humano, la arquitectura debe también corresponderse y comprometerse con la ampliación de los horizontes humanos. Esta es la concepción fundamental que vigora en La corona de la ciudad. Comprender la arquitectura tan sólo a partir de su carácter utilitarista, hace de ella una especie de "arte aplicada", algo que expone una interpretación simplista, cuando no despreciativa, de su importancia:

Precisamente es en los edificios que se construyen por algo más que la mera necesidad donde la arquitectura se manifiesta como arte, como juego de fantasía que ha perdido casi toda relación con la utilidad. Sin embargo, ninguna actividad de la 
imaginación humana es capaz de producir formas sólidas y profundas si no radica en la vida interior y moral del hombre, en todo el conjunto de su sentimiento existencial. Así pues, si se asigna a la arquitectura un puesto tan modesto, no debería uno conformarse con explicar su origen a partir de la utilidad, sino que habría que hacer una interpretación más amplia y absolutamente abierta de dicha utilidad. (TAUT, 1997, p.38)

La característica fundamental de la arquitectura, su capacidad de imaginar formas es interpretada ahora de un modo más amplio y libre de toda utilidad. Lo que propone Taut es que la arquitectura sea pensada más allá de la esfera de las necesidades y vicisitudes que congregan la existencia humana, procurando establecer una interpretación que considere su origen en la creatividad del espíritu y del pensamiento humanos. Por esa interpretación, el construir debe antes corresponder a un determinado modo de habitar el mundo, un modo necesario y libre de cualquier coerción. Por otra parte, la correspondencia entre lo exterior y lo interior del ser humano es determinante para la instauración del mundo. La existencia demanda la insistencia de lo humano en construir de forma incesante un mundo que ya y siempre no puede sino sucumbir al tiempo. Este corresponder al mundo interior y espiritual, no significa la adopción de un sentido pragmático o de reglas de construcción, sino un encuentro con algo que transciende la esfera de la utilidad humana y que vigora allí donde solo lo necesario puede tener lugar. Tal encuentro debería ser el punto de partida para los nuevos tiempos que la humanidad aspiraba en el comienzo del siglo 20, en un mundo determinado por la post-guerra. En aquella época, y aún hoy, se trataba de descubrir las "potencias aún latentes del alma", "la esperanza", "los deseos" para entonces poder "construir en un sentido más elevado", (TAUT, 1997, p. 38). Nuevos tiempos para la humanidad y también para el arquitecto que debe, según Taut,

recuperar su excelsa, sacerdotal y divina profesión y procurar desenterrar el tesoro que yace en las profundidades del espíritu humano. Renunciando por completo a sí mismo, logrará internarse en el alma del conjunto del pueblo y encontrarse a sí mismo y a su eminente profesión, siempre y cuando proporcione, al menos como objetivo, una expresión convertida en materia a lo que late oculto en todo humano". $(1997$, p.47)

La elevación del arquitecto no podría ser mayor: ser capaz de traer a la superficie lo que "late oculto en todo humano". En el interior del espíritu humano, entiende Taut, debe quedar algo que lo eleve por encima de lo temporal, que le permita sentirse en relación con su entorno y con los hombres del mundo entero, "algo que está esperando su resurrección, su radiante transfiguración y cristalización en edificios gloriosos?" (1997, p.46). Es tarea del arquitecto, de un modo material, lograr, o a menos intentar, construir edificios que den plasticidad a las profundidades del espíritu humano. Ya no debería sólo tratar de construir orientado por cierta finalidad de orden práctica y útil, sino desde una voluntad libre, "renunciando por completo a sí mismo". Por ello, afirma Taut:

lo que constituye la voluntad del arquitecto es algo totalmente diferente de la sujeción a un fin determinado; que esa voluntad se halla por encima de lo propiamente práctico, y que su máxima aspiración son los edificios cuya utilidad práctica es muy escasa o incluso nula. (1997, p.38) 
La aspiración del arquitecto y la construcción de edificios de poca o ninguna utilidad son los fundamentos de la corona de la ciudad. Ahora bien, pero ¿qué eso de lo no útil, donde la arquitectura se muestra con más intensidad? ¿Cómo describir en síntesis lo que sólo se puede construir?, se pregunta Taut (1997, p.59). En Arquitectura Alpina, obra contemporánea de La corona de la ciudad, aborda la cuestión directamente:

¡Nada práctico, ninguna utilidad! Pero ¿acaso lo útil nos ha hecho felices? Se habla una y otra vez de utilidad, de confort, de comodidad, de buena comida, de educación -cuchillo y tenedor - de ferrocarriles, de retretes y, naturalmente, también de cañones, bombas y otros pertrechos homicidas. Querer simplemente lo útil y lo cómodo sin una idea superior equivale al aburrimiento. Y el aburrimiento acarrea la disputa, la querella y la guerra. (2011, p.66)

Lo que permanece latente en el interior humano debe ser despertado por el arquitecto, y ello no corresponde a lo útil que prodigiosamente los objetos técnicos conllevan. Estos tienen su lugar y, evidentemente, su utilidad, pero ello no significa que la experiencia humana pueda ser limitada a "Io simplemente útil y cómodo". El alma humana clama "pidiendo por algo superior, algo que la eleve por encima de la existencia cotidiana". (TAUT, 1997, p.49). Saber escuchar ese clamor es la tarea del arquitecto, que "pugna por hallar una expresión suprema" (1997, p.59). En ello consiste la corona de la ciudad, cuyo emblema o ícono es la Casa de Cristal:

un edificio más alto, el cual despojado por completo de toda finalidad, reina sobre el conjunto al modo de una arquitectura pura. Se trata de la casa de cristal, realizada a base de vidrio, un material de construcción que denota materia, pero también algo más que una materia corriente, dadas sus características de brillo, transparencia y reflejo". (1997, p. 59)

En la concepción de la Casa de Cristales necesario considerar la relación de amistad e inspiración que Taut nutría por el poeta y escritor Paul Scheerbart (1863-1915), cuya presencia es evidente en la obra de Taut y algunas de las intuiciones presentes en los aforismos de Arquitectura de Cristal que escribió Scheerbart serían decisivas para el desarrollo de la arquitectura tautiana. Aunque haya sido teorizada y calculada de modo más detallado en La corona de la ciudad, la Casa de Cristal se concretizó algunos años antes. En 1914, Taut participa de la Exposición Industrial promovida por la Deutsche Werkbund en Colonia, atrayendo una multitud de visitantes para su creación, la Casa de Cristal (Glashaus), un pabellón de vidrio construido con los nuevos materiales de la época, hierro, hormigón y, sobre todo, el vidrio. Toda la construcción permitía que la luz invadiera y dominara el ambiente (Figura 1). En su interior, una cascada (Figura 2) colaboraba con la creación de un lugar fantástico e inhabitual. Taut también incluyó inscripciones en homenaje a Scheerbart, entre otras: "La luz se extenderá por todo el universo y estará viva en el cristal", "el vidrio trae una nueva era", "sin un palacio de cristal la vida es una carga", "el vidrio colorido destruye el odio" y "qué sería de la construcción sin el hormigón" (FRAMPTON, 2002, p.118). De la relación entre el arquitecto y el poeta, es significativa la justificación de utilizar los nuevos materiales en busca de una mudanza ética radical, objetivo principal de la arquitectura de cristal, "Ilevando la cultura a un nivel superior" proclamaba Scheerbart (SHARP, 1972, p.41). 

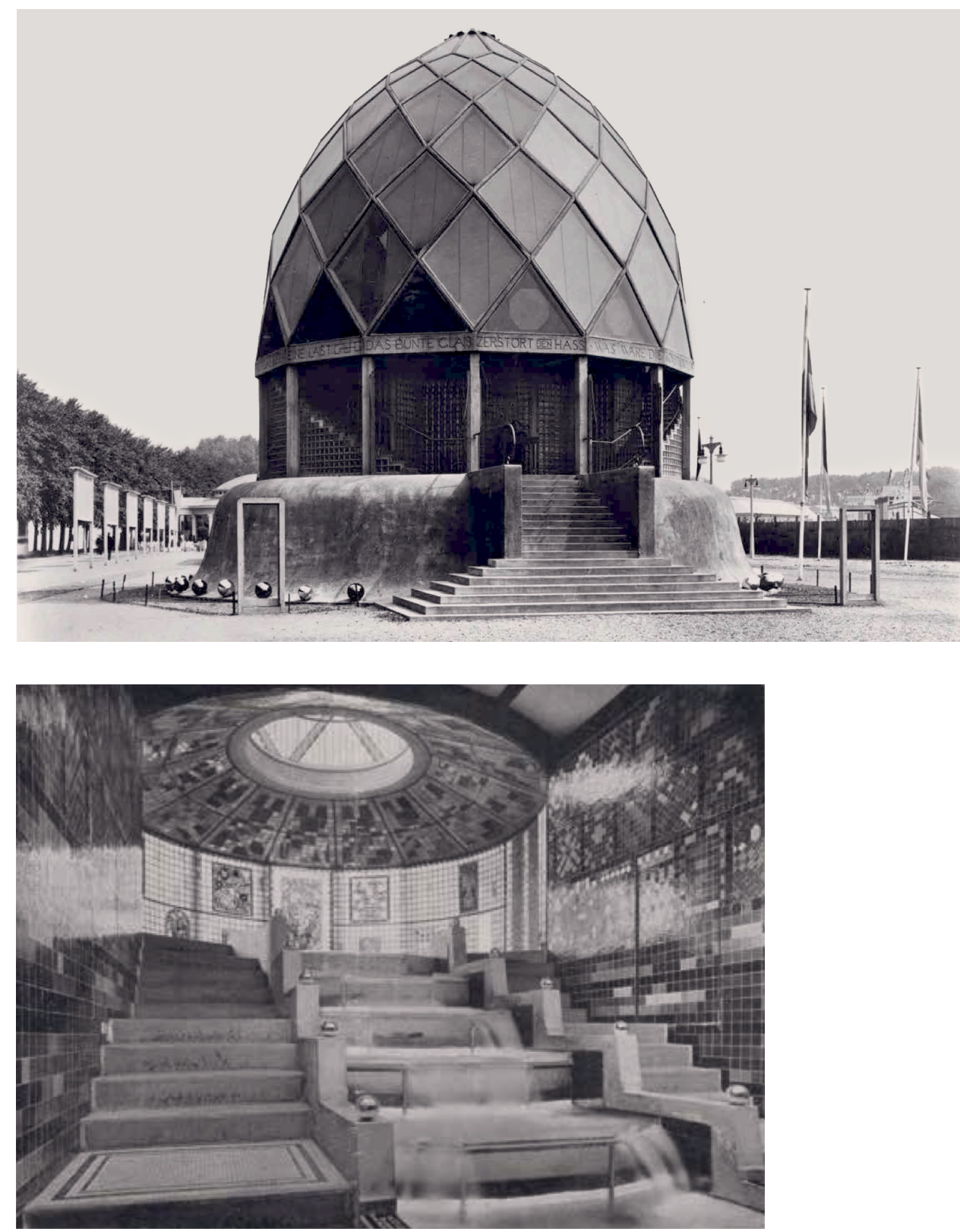

Figura 1: Casa de Cristal, Colonia, 1914. Recuperado de TAUT, 1997, p.18.

Figura 2: Casa de Cristal (interior), Colonia, 1914. Recuperado de TAUT, 1997, p. 19.
Aproximando la arquitectura da poesía, Taut busca por las potencialidades artísticas del material, "como una posibilidad de incrementar el placer estético de la humanidad" (MARCHÁN FIZ, 2008, p.62). Como explicaba el folleto de divulgación de la Casa de Cristal, su "única finalidad era ser bella". Para ello se requiere una renovación técnica que pasa por la adopción de los nuevos materiales que, muy acorde al sentimiento expresionista, "se convierten en expresiones de una interpretación personal y emotiva de la realidad, con un proyecto que nace de la necesidad de ultrapasar el mero funcionalismo, constituyendo una inagotable reserva de sugerencias" (PRISCO, 2017, p.10). Con esas consignas, la Casa de Cristal expresa la posibilidad de construir de un modo libre, hace ver la posibilidad de lugares que dan cobijo y plasticidad a una 
reserva de un sentido por el cual la arquitectura explicita su esencia y ésta algo de propio del ser humano - se construye porque se habita (HEIDEGGER, 2006) - lo que no significa limitarse a cumplir con determinada funcionalidad, sino algo más allá que da sentido a todo construir. Para Taut la Casa de Cristal es un "símbolo de la mayor serenidad, de la más pura tranquilidad del alma", el "prototipo de una sensibilidad cósmica de una religiosidad que sólo puede guardar un silencio reverente" (1997, p.60), una construcción que toma su fuerza desde un sin porqué, una obra que supera toda utilidad si se la considera desde las necesidades existenciales del ser humano, pero que resulta un necesario "sin porqué" cuando se la ve desde la libertad que proporciona el ser inútil.

Como símbolo y prototipo, la Casa de Cristal es la indicación de que la arquitectura puede conducir el alma humana a algo superior. Puede suscitar experiencias que sobrepasan las relaciones útiles que ocupan la labor cotidiana incesantemente impuesta por la existencia humana. Señala lo verdaderamente superior, sobre el cual, poco o nada se puede decir. Y es justamente aquí, en la cumbre de su proyecto y de su concepción arquitectónica, donde Taut hace suyas las palabras eckhartianas para describir la experiencia promovida por su construcción:

Lo supremo es siempre vacío y silencioso. Ya lo dijo el Maestro Eckhart: "jamás pediré a dios que se me entregue; le pediré que me vacíe y me purifique. Pues si yo estuviera vacío y puro, Dios, por su propia naturaleza, tendría que entregarse a mí y llenar mi vacío". (1997, p.61)

El proverbio eckhartiano guarda las enseñanzas fundamentales del místico renano y corresponde a los propósitos del arquitecto. La búsqueda del vacío es la necesaria condición para dios tenga lugar en el alma despojada. Conquistar tal condición es lo que, como vimos, significa el vivir sin porqué eckhartiano. Del mismo modo que el alma debe vaciarse y purificarse completamente, dando lugar al puro nada, uniéndose al dios más allá de dios, haciendo que dios se entregue y ocupe el lugar que más le conviene, también el arquitecto debe construir lugares que señalen la libertad como condición fundamental del ser humano y de la propia arquitectura. La aspiración humana del más allá se materializa en la Casa de Cristal. Ya fue dicho que la arquitectura tautiana podría corresponder a un "misticismo terrenal" (ABALOS, 1997, p.10) o a un "materialismo místico" (NAJLE, 2011, p.133), por ser capaz de engendrar una transformación del modo del ser humano habitar la tierra y construir su mundo.

\section{Consideración final}

El impacto del místico renano en el pensamiento tautiano es evidente. Las referencias explícitas están lejos de ser meras notas de erudición, ellas evidencian un apoyo y una inspiración. Eckhart importa a Taut porque en él puede encontrar un fiel colaborador. Incluso cuando Taut no menciona el maestro renano no es difícil reconocer su presencia y recordar la fuerza especulativa de su pensamiento, como, por ejemplo, en la última y no menos significativa lámina (Figura 3) de Arquitectura Alpina: la Gran Nada, lo sin nombre (Das Grosse Nichts; Das Namenlose). Aprender a relacionarse con esa Nada, nombre del más allá y de lo inefable, es el destino de todo ser humano. También el arquitecto se enfrenta a ese destino y lo hace construyendo lugares que suscitan una 
Figura 3: La Gran nada, lo sin nombre. Recuperado de Taut, 2011, p. 99.

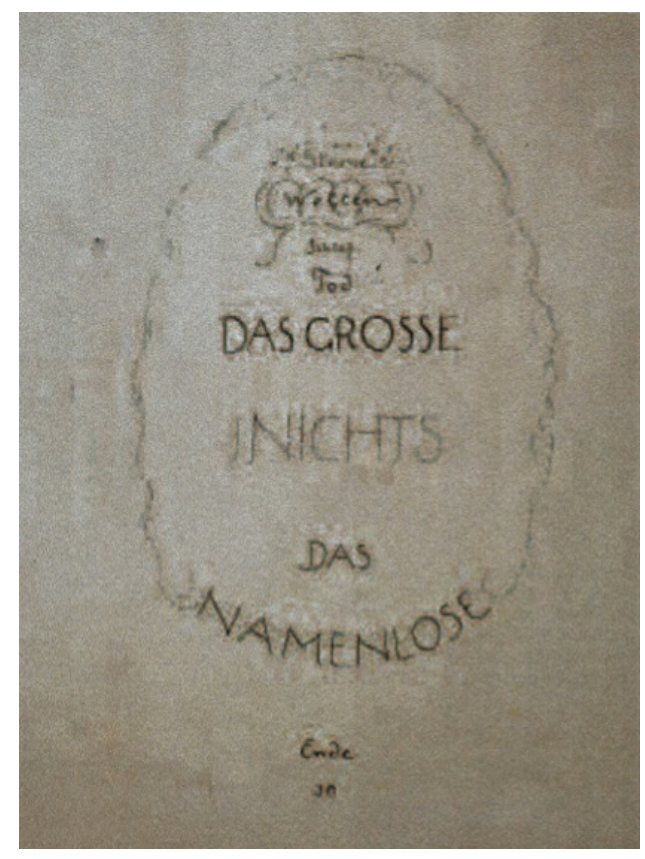

experiencia proyectada para dar a conocer algo que está más allá de la esfera humana, permitiendo ver una relación fundamental con esa misma Nada, con lo sin-nombre. La concepción tautiana cuida que el sentido de ese más allá conquiste un lugar en la existencia humana, bajo la bandera y el estímulo teórico de lo que aquí denominamos de arquitectura sin porqué. Nada podría ser más eckhartiano.

\section{Referencias bibliográficas}

ÁBALOS, Iñaki. "Taut, el eterno retorno". In: TAUT, B. Escritos Expresionistas (Introducción) 1997, pp.7-31

BOYD WHYTE, Iain. The Crystal Chain Letters. Architectural Fantasies by Bruno Taut and his Circle, Cambridge, Massachusetts, MIT Press, 1985.

Bruno Taut and the Architecture of Activism, Cambridge, Cambridge University Press. 1982.

CIRLOT, Victoria. "El Maestro Eckhart y la arquitectura de Bruno Taut". In: Mística y creación en el S. XX, Barcelona, Herder, 2013, p.122-148.

FRAMPTON, Kenneth. Historia Crítica de la arquitectura moderna, Barcelona, Ediciones GG, 2002 HAAS, Alois Maria. Maestro Eckhart, Barcelona, Herder, 2002.

HEIDEGGER, Martin. Die Kehre, (Trad. Maria Cristina Ponce Ruiz) Córdoba, Alción, 2008.

"Construir, Habitar, Pensar". In: Ensaios e Conferências, Petrópolis, Vozes, 2006, pp.125-141.

MARCHÁN FIZ, Simón. La metáfora del cristal en las artes y en la arquitectura, Madrid, Siruela, 2008. 
MEISTER ECKHART. Tratados y Sermones(Trad. Ilse Brugger), Buenos Aires, Las Cuarenta, 2013.

NAJLE, Ciro. "Esencias superfluas. El materialismo místico de Bruno Taut". In: TAUT, B. 2011, pp.133-135.

NERDINGER, W. ET AL. Bruno Taut 1880-1938, Milano-Roma, Electa, 2001.

NIETZSCHE, Friedrich. Nachgelassene Fragmente, Kritische Studienausgabe Band 12, Deutscher Taschenbuch, Berlin-New York, Verlag de Gruyter, 1999. 2005.

"Die Fröhliche Wissenschaft", In: Gesammelte Werke, Bindlach, Gondrom Verlag,

PRISCO, Valentina. "Bruno Taut e il paradiso di vetro", Architetture Nascoste <architetturenascoste.files.wordpress.com/2017/04/bruno-taut-e-il-paradiso-di-vetro.pdf>, acceso: 10/10/2018.

SCHIRREN, Matthias. "Natura, cosmo, Weltbild, proporzione. Bruno Taut Teorico". In: NERDINGER, W. et Al (2001) pp.91-113

SHARP, Dennis Glass Architeture by Paul Scheerbart and Alpine Architeture by Bruno Taut, New York, Praeger Publishers, 1972.

TAUT, Bruno. Arquitectura Alpina, Edición de Iñaki Ábalos, Madrid, Círculo de Bellas Artes, 2011. Escritos Expresionistas, Madrid, Croquis, 1997. 